\title{
Comparative Analysis of the Russian and Australian Legislation on Toxic Gases after Blasting
}

\author{
E.A. Medova, M. L. Rudakov \\ Saint-Petersburg Mining University, Mining department, 2, 21st Line, St Petersburg 199106, Russia
}

\begin{abstract}
The article provides an analysis of Russian and Australian national documentation on occupational safety and industrial safety for toxic post-blast gases. The main purpose of the article is to present the results of research on the need for a recognized document that would be appropriate for the all countries conducting open cut blasting. The research was performed with two spheres of mine safety in mind, such as occupational health and safety to establish standards for environmental exposure to harmful gases and an industrial safety to establish the sequence of blasting operations to prevent the spread of post-blast gases. In addition, a brief description of the key parameters to be included in the documentation is included.
\end{abstract}

\section{Introduction}

Nowadays, blasting activities are an inherent part of the world industry. Blasting works are conducted prevalently in the mining sector of the industry, especially open-pit mining, and in building and construction. Although blasting works is one of the most effective ways of exploitation and it exerts a considerable impact on further processes making them more efficient, e.g.,the filling of solid rocks pieces after blasting is of adequate size to run the mill at the highest level of productivity, this kind of mine development is not perfect because of fuming which is a combination of post-blast toxic gases like NO2(nitrogen dioxide), NO (nitric oxide), and $\mathrm{CO}$ (carbon monoxide).A lot of scientists have been considering the influence of NO2 after blasting works; [1] in their works showed that the efficiency and safety of blasting work mainly depends on prevention of the nitrogen dioxide emissions.As for foreign scientific research in the field of fuming, Australian scientists Glenn B. Stracher, Anupma Prakash, and Ellina V. Sokol in their work Coal and Peat Fires: A Global Perspective pay attention to the spontaneous combustion of gases in open-cut mining. Occupational safety and health issues in open-pit mining still demand attention and action due to the high rate of increase in the number of occupational accidents and diseases worldwide caused by the lack of universally recognized legislation regarding fuming.

It is important to note that nitrogen dioxide (NO2) is one of the most harmful gases. It generates from the combination of nitric oxide and oxygen in the atmosphere of post-blast gases as the result of non-ideal explosive reactions that can ensue caused by many factors, e.g., using non- or over-fuelled ammonium nitrate (AN), poorly mixed AN mixture, density 
of loaded explosives, formulation of the mixed explosives, deteriorations during delivering and loading, firing the explosives, explosives product selected being not suitable for the prevailing conditions, mistakes by blasting personnel. It is important to underline that other hazardous gases occur for the same reasons, and one of the examples is the occurring of sulphur dioxide considered by V. I. Chernobay in his article. Nitrogen dioxide can be identified by vision or by using gas analyzers. However, the choice of the most suitable kind of gas analyzer can influence the result, and this issue has been considered in the work by scientists $[2,3]$. Nitrogen dioxide is a yellow, orange, or brown-colored, acrid-smelling gas. It is heavier than air and is sparingly soluble in water, and this chemical property is the reason why nitrogen dioxide has a quite long latent period. Either an acute exposure to a significantly high dose causes respiratory problems such as RADS (Reactive Airways Dysfunction Syndrome) and a possible fatal outcome, or long-term inhalation results in wheezing, coughing, colds, flu, and bronchitis. For mining workers on the open-pit, there is a great chance to get specific illnesses because nitrogen dioxide is less water-soluble, so a full inhalation may occur before the poisoning is detected causing serious damage to the alveoli may be damaged a lot. The higher concentrations of nitrogen dioxide cause bronchospasm and pulmonary edema, which lead to drowning effect due to fluid-filled blisters bursting in the lungs. In the case of fuming after blasting operations on the openpit, short-term exposure takes place more often, so in the context of occupational safety, acute contamination is supposed to be one of the biggest hazards for miners. Indeed, it is extremely complicated to manage the fuming process because it depends on the abundance of external causes, and some of them cannot be monitored during the entire blasting process, e.g., weather conditions and the moisture of the boreholes. Although there are effective methods that can decrease the concentration of nitrogen dioxide after blasting,e.g., using the catalysts during pre-blasting works like $[1,4,5]$ have offered in their scientific works, the monitoring of fuming mainly depends on the documentation in the field of fuming.

\section{Methodology}

Nitrogen dioxide can cause acid rains and poison the atmosphere due to spreading fume clouds; it also affects prevalently on workers' health and life, and it is the main concern of occupational safety. But other than that, in accordance with Federal Law No. 116-FZ of July 21, 1997 "On Industrial Safety of Hazardous Production Facilities," open-pit mines are considered hazardous production facilities (of II, III, or IV hazard category). Therefore, facilities that have been defined as hazardous must meet the requirements of the legislation in this sphere.

The idea of the method is a comparison of the legislation of the Russian Federation and the foreign legislation by dividing all documents into two main sectors, s specifically, the sphere of occupational safety and the sphere of industrial safety. In order to conduct a comparative analysis, the Russian and Australian legislations were chosen due to the competence of both countries in the management of fumes. It can be attributed to the abundance of Australian companies that proceed blasting operations worldwide and a huge amount of open-pit mines in Russia.

The purpose of the comparative analysis of regulations and requirements was to identify their common and distinguishing matters, to consider the need for legislation for the fuming issues that would be appropriate worldwide.

At present, in Russia, exposure limits are established by the hygienic norms GN 2.2.5.3532-18 "Maximum permissible concentrations (MPC) of harmful substances in the air of the working zone". Besides, the scope of these requirements is established by the "Methodology for special assessment of working conditions", approved by order of the 
Ministry of Labor and Social Protection of the Russian Federation N 33n. dated January 24, 2014 With respect to Australian law, the "Standardsfor Workplace Exposure to Airborne Contaminants" (effective date: 27 April 2018), establish hygienic standards and procedures for duties under the Occupaional Health and Safety (OHS) Act and the OHS Regulations.

Meanwhile, as an example of industrial safety issues, the measurements of hazardous process parameters, the blasting process itself, and the control of fumes were chosen. Companies that conduct blasting operations in Russia must follow regulations which are adjusted by the Order of the Federal Service for environmental, Technological and Nuclear Supervision N 605 of December 16, 2013 "On approval of federal norms and rules in the field of industrial safety. Safety rules for blasting". Referring to the Australian management of oxides of nitrogen, the following regulations are established by the Mining and Quarrying Safety and Health Act 1999 (MQSHA) and the Explosives Act 1999 [6, 7, 8].

\section{Results}

As the first stage of this comparison, two different kinds of exposures were analyzed for the open-cut blasting. It is self-evident that Time Weighted Average Standard is not appropriate for this kind of works because of the inability to register a high concentration of nitrogen dioxide during the entire shift. Due to that, the Short Term Exposure Limit (STEL) was chosen as the basic exposure standard for nitrogen dioxide because the high-intensive exposures cause adverse health outcomes more frequently. Itshould be noted that occupational exposure standards in Russia are much stricter than in Australia. In the documents mentioned in the division "Methodology in Russia," the main toxicology standards for gases with irritant effect are demonstrated in the "List of Irritating Substances" table (Table 1) $[9,10,11]$.

Table 1. Occupational Exposure Standards for $\mathrm{NO}_{2}$ in Russia.

\begin{tabular}{|c|c|c|}
\hline Chemical name & STEL, $\mathrm{mg} / \mathrm{m}^{3}$ & Hazard category \\
\hline $\begin{array}{c}\text { Nitrogen dioxide } \\
\text { (Nitrogen (IV) oxide) }\end{array}$ & 2.0 & 3.0 \\
\hline
\end{tabular}

However, in Australia, Short Term Exposure Limit is evaluated not only in $\mathrm{mg} / \mathrm{m} 3 \mathrm{but}$ also in ppm (Parts of vapor or gas per million parts of contaminated air by volume). In the above documents, the information about occupational exposures can be found in the "List of Occupational Standards" (Table 2).

Table 2. Occupational Exposure Standards for $\mathrm{NO}_{2}$ in Australia

\begin{tabular}{|c|c|c|}
\hline Chemical name & STEL, $\mathrm{ppm}$ & STEL, $\mathrm{mg} / \mathrm{m}^{3}$ \\
\hline Nitrogen dioxide & 5.0 & 9.4 \\
\hline
\end{tabular}

As for industrial safety, "Safety Rules for Blasting" in Russia establish requirements to the natural and artificial covers generally intended to protect from the post-blasting hazards, in particular, fuming. To calculate the dimension of the hazardous zone during the blasting process in case of using more than 200 tons of pin-point blasting charge, which put bounds to contamination of post-blast toxic gases, the formulas in items No. 863 (Formula 1) and No. 864 (Formula 2) can be used. There are two formulas for two cases; for example, in the event of absence of the wind or when it has perpendicular direction the radius of the safe zone can be calculated by formula (1) and in the event of the straight direction by formula (2). 


$$
r=160 \cdot \sqrt[3]{Q}
$$

Where $r$ = radius of the hazardous zone; $Q=$ mass of the pin-point blasting charge.

$$
r=160 \cdot \sqrt[3]{Q} \cdot(1+0,5 \cdot V)
$$

Where $V=$ speed of the wind before blasting.

In accordance with Australian regulations, there is a Queensland Guidance Note QGN $20 \mathrm{v} 3$ that contains the information from the regulations not only mentioned in the previous section but also from Mining and Quarrying Safety Bulletin 61 "Flammable and toxic gases in open cut coal mines", Explosives Safety Alert 44 "Prevention and management of blast fumes", and Explosives Safety Alert 28 "Post blast gases". To identify the internal and external potentially exposed sites, a master fume map should be developed. The potential dimensions of the hazardous zone can be found in the Guidance Note (Table "Length of potential exclusion distance downwind $(\mathrm{m})$ with several different wind conditions covering the daytime stability classes"); it takes into consideration wind characteristics as they are in Russian formulas. The map included in Australian documentation contains much more information and it has different classes of fumes and weather stability classes thatcause fumes themselves, but this map is only consideredonly indicative. The Guidance Note also provides data on gases to determine their class by vision, which makes the Note application-oriented $[12,13,14]$.

The absence of a worldwide-recognized sequence of rules that could be used to estimate the professional risks is obvious. On the one hand, Russian documentation does not take into consideration weather conditions and classes of fumes, and it is not oriented for personnel application. On the other hand, the parameters that are regarded in the Australian documents do not include field measures to assess the risk at a particular time; the Australian system is based on predictions, which are hard to make in the case of frequently changing atmospheric conditions.

\section{Discussion}

To confirm the necessity of the management system for fumes it should be noted that one of the most harmful hazards in open-cut blasting is $\mathrm{NO}_{2}$ fumes caused by theirability to spread for great distances. It can be dangerous to personnel of the whole mine even in the external zone of blasting. Another problem of occupational safety is the differences for occupational exposure standards. As it was mentioned in the section "Introduction", the preparation of the non-ideal mixture of the explosives causes fumes but it is obvious that for most of the production companies it is not economically advantageous. It is more rentable to prepare a non-ideal mixture using cheaper raw materials and to estimate the quantity of nitrogen dioxide for the final product after blasting. Therefore, the quantity in Australia is not at the acceptable for Russia level. The importance of the combination with the right conditions has been considered in the work by scientists P. Afanasev, S. Khokhlov, V. Isheyskiy $[15,16,17]$.

However, the parameters that are considered in both legislations can be used as the basis for the international regulations because the Order of the Federal Service for Environmental, Technological and Nuclear Supervision N 605 of December 16, 2013 "On approval of federal norms and rules in the field of industrial safety. Safety Rules for Blasting" takes into consideration the final mass of the explosives and establishes time to continue works held on the bench, which is not restricted in Australian legislation. However, there are many scientists in Russia who have considered the importance of calculation of the parameters of the blast zone, and the way to calculate it can be found in 
the works of G. P. Paramonov and V.V. Lisevich. On the other hand, Queensland Guidance Note QGN 20 v 3 presents a full list of reviews, e.g., pre-firing review, blasting process review, post-blasting review, and includes sections from Australian legislation in quarrying and mining safety to archive one of the occupational safety duty, in particular, to make safety documentation available for use not only for executives but also to workers. To sum up, in this study, the differences in the legislation of the Russian Federation and Australia in the field of monitoring of the $\mathrm{NO}_{2}$ were reviewed and, consequently, the studydescribes cases of inhalation of high concentrations due to different degree of awareness of miners and their ability to resist different concentrations. There is also the absence of a unified method to calculate the parameters of the danger zone, so the damaging influence of the fuming cloud both on the personnel and environment cannot be clearlypredicted [18].

At the same time, the development of international legislation provides for certain restrictions in establishing requirements:

1.The lowest occupational exposures should be accepted worldwide in order to not infringe existing national legislations

2.In developing the dimension of the safe zone, all climate zones should be considered

3.The document should include two ways to estimate the $\mathrm{NO}_{2}$ characteristics, in particular, by vision with examples of descriptions and by monitoring gas analyzers (personal and immobile).

\section{Conclusions}

The management of nitrogen dioxide still demands the consideration of occupational safety because it is a rapid hazard that cannot be one hundred percent predicted at the pre-blasting stage and monitored during the entire shift. Therefore, the absence of international regulation can provide more factors that occur fuming.

In accordance with the investigations performed, it is possible to state that it necessary to establish worldwide standards in this sphere due to the abundance of international blasting companies that must meet the requirements of the countries they work in.

It is worth underlining that it is important to take into consideration all blasting stages and to include monitoring of fumes during all of them,startingwiththe preparation of the explosives and estimating professional risks. In addition, it is important to develop the Guidance Note to working personnel to make the legislation more user-oriented.

\section{References}

1. R.S.Babkin, G.P. Paramonov, Reducing Nitrogen Oxides Emission During Blasting Works.Monitoring. Science and Technology, 2,31-34(2018).

2. D.V. Moldovan, V.I. Chernobay, K.N. Yastrebova, Socio-economic and environmental problems of the mining industry, construction and energy: collection of materials of the 15th International conference on the problems of mining, construction and energy, October 29-30(2019)

3. V.I. Chernobay, Reducing the emission of sulfur dioxide during blasting operations in pyrite mines, Notes of the Gorny Institute, 155(1), 93-97 (2003)

4. P.I., Afanasev, K. Sergey,I. Valentin, The Equation of State for Explosive Detonation Products. International Journal of Mechanical Engineering and Technology, 9(13),865-868(2018).

5. G.P.Paramonov,V.V. Lisevich, Forecasting of Parameters of a Rock Mass Collapse WhenBlasting Work, International Research Journal, 4(46),100-103 (2016) 
6. R.J. Mainiero, J.H. Rowland III, M.L. Harris, M.J. Sapko,Behavior of Nitrogen Oxides in the Product Gases from Explosive Detonations. Proceedings Of The Annual Conference on Explosives and Blasting Technique, 2, 93 (2006)

7. Coal Mining Safety and Health Act: current as of 10 November 2019(The State of Queensland, 2019)

8. Explosives Act 1999 No. 15: date of assent 22 April 1999(The State of Queensland, 2014).

9. Prevention and management of blast fumes. Explosives Inspectorate Safety Alert,44: 15 March 2011(The State of Queensland, 2011).

10. Post blast gases. Explosives Inspectorate Safety Alert,28:09 July 2009(The State of Queensland, 2009).

11. M.L.Harris, R.J.Mainiero, Monitoring and removal of $\mathrm{CO}$ in blastingoperations, SafetyScience, 46(10), 1393-1405. 2008.

12. On the approval of hygienic standards GN 2.2.5.3532-18 Maximum permissible concentrations $(M P C)$. - Resolution of the Chief State Sanitary Doctor of the Russian Federation dated February 13, 2018, No. 25(Collectionoflegislation, 2018).

13. On the approval of federal norms and rules in the field of industrial safety Safety Rules for Blasting. - December 16, 2013, No. 605. (Collection of legislation, 2013).

14. On approval of the Methodology for the special assessment of working conditions, the Classifier ofharmful and (or) hazardous production factors, the form of the report on the specialassessment of working conditions, and instructions for its completion. - the Order of the Ministry of Labor and Social Protection of the Russian Federation of January 24, 2014, No. 33n. . (Collection of legislation, 2014).

15. R. Farnfield, A.Wetherelt, After-blast fumes from ANFO mixtures: the effect of prill type and mixing technique. Quarrymanagement: 11-19(2004).

16. Mining and Quarrying Safety and Health Act 1999: current as of 30 June 2017.(The State of Queensland, 2017).

17. M.S. Wieland,Toxic Fumes on the Rocks.Conference on Explosives and Blasting Technique, Proceedings Of The Twenty Eighth Annual Conference On Explosives And Blasting Technique, 2, 14 (2005).

18. D.V. Moldovan, Factors of atmospheric pollution of coal pits and open-pit coal mines during drilling andblasting operations and methods of their determination, Collection of materials The 15-th International Conference on the Mining Industry, Building and Power Engineering Problems, 1, 355-360 (2019) 